Borgsteede, S.D., Deliens, L., Zuurmond, W.W.A., Schellevis, F., Willems, D.L., Wal, G. van der, Eijk, J.T.Mt van. Prescribing of pain medication in palliative care: a survey in general practice. Pharmacoepidemiology and Drug Safety: 2009, 18(1), 16-23

\begin{tabular}{|l|l|}
\hline $\begin{array}{l}\text { Postprint } \\
\text { Version }\end{array}$ & 1.0 \\
\hline Journal website & $\underline{\mathrm{http} / / / \mathrm{www} 3 . \text { interscience.wiley.com/journal/121500609/abstract }}$ \\
\hline Pubmed link & $\underline{\mathrm{http} / / \text { preview.ncbi.nlm.nih.gov/pubmed/18985638 }}$ \\
\hline DOI & $10.1002 / \mathrm{pds} .1678$ \\
\hline
\end{tabular}

This is a NIVEL certified Post Print, more info at http://www.nivel.eu .

\title{
Prescribing of pain medication in palliative care. A survey in general practice ${ }^{\mathrm{y}}$.
}

SANDER D. BORGSTEEDE ${ }^{1,2^{*}, z}$, LUC DELIENS ${ }^{1,3 x}$, WOUTER W. A. ZUURMOND ${ }^{4}$, FRANC, OIS G. SCHELLEVIS $^{5,6 \mathrm{~K}}$, DICK L. WILLEMS ${ }^{7 \#}$, GERRIT VAN DER WAL ${ }^{1 \mathrm{~K}}$ AND JACQUES TH. M. VAN EIJK ${ }^{8 * *}$.

${ }^{1}$ VU University Medical Center, Department of Public and Occupational Health, EMGO Institute, Amsterdam, The Netherlands.

${ }^{2}$ VU University Medical Center, Department of Clinical Pharmacology and Pharmacy, Amsterdam, The Netherlands.

${ }^{3}$ Vrije Universiteit Brussel, End-of-Life Care Research Group, Brussels, Belgium.

${ }^{4}$ VU University Medical Center, Department of Anesthesiology/Pain Clinics, Amsterdam, The Netherlands.

${ }^{5}$ VU University Medical Center, Department of General Practice, EMGO Institute, Amsterdam, The Netherlands.

${ }^{6}$ Netherlands Institute for Health Services Research, Utrecht, The Netherlands.

${ }^{7}$ Academic Medical Center, Department of General Practice, University of Amsterdam, Amsterdam, The Netherlands.

${ }^{8}$ Department of Health Care Studies/Medical Sociology, University of Maastricht, Maastricht, The Netherlands.

* Correspondence to: S. D. Borgsteede, Department of Public and Occupational. Health, VU University Medical Center, Van der Boechorststraat 7, 1081 BT Amsterdam, The Netherlands.

E-mail: s.borgsteede@vumc.nl yNo conflict of interest was declared.

${ }^{\mathrm{z}}$ Pharmacist.

${ }^{\mathrm{x}}$ Medical sociologist.

-Anaesthesiologist.

${ }^{\mathrm{k}}$ General practitioner.

\#General practitioner and ethicist.

${ }^{* *}$ Medical sociologist end epidemiologist.

\section{SUMMARY}

Purpose To examine what pain and adjuvant medication is prescribed in palliative care patients at home in The Netherlands.

Methods In a nationwide, representative, prospective study in general practice in The Netherlands, prescribed medication was registered in 95 general practices with a listed population of 374070 patients. The GPs identified those who received palliative care in a retrospective survey of the 2169 patients who died within the 1-year study period. We analysed the analgesics, laxatives and anti-emetics that were prescribed during the last 3 months of life for these patients.

Results The response rate of the survey was $74 \% .425$ patients received palliative care and $73 \%$ of them were prescribed pain medication: $55 \%$ a non-opioid analgesic (paracetamol, NSAIDs), 21\% a weak opioid (tramadol, codeine), and 51\% a strong opioid. Relatively more younger than older patients were prescribed strong opioids, and more cancer than non-cancer patients were prescribed an analgesic. During the last 3 months of life, the proportion of patients prescribed a non-opioid or a weak opioid increased gradually. The proportion of 
patients prescribed a strong opioid increased considerably nearing the patient's death. About one third of the non-cancer patients were prescribed strong opioids, mostly commencing in the last 2 weeks before death. In $48 \%$ of all patients with an opioid prescription, the GP did not prescribe a laxative.

\section{INTRODUCTION}

Most people with an incurable disease prefer to remain at home surrounded by their relatives during the last part of their lives. ${ }^{1-3}$ In The Netherlands, health care is characterised by its strong emphasis on primary care, where the general practitioner (GP) is the central professional in the management of the patient's treatment. ${ }^{4}$ Almost $60 \%$ of patients with non-acute illnesses die at home, ${ }^{5}$ and there is a general consensus that palliative care should be provided in the patient's home. ${ }^{6}$ Pain is one of the symptoms that physicians most frequently encounter in palliative care patients. ${ }^{7,8}$ An important aid for pain management is theWorld Health Organisation (WHO) analgesic ladder. ${ }^{9}$ Drug treatment is the mainstay of pain management and is composed of three steps of pharmacological therapy. The sequential use of drugs starts with the non-opioid analgesics in step 1, as well as adjuvant drugs. ${ }^{9}$ Opioids for mild to moderate pain — weak opioids - are prescribed in step 2 and strong opioids for moderate to severe pain in step 3. In most patients it is possible to manage pain effectively ${ }^{10}$; however, substantial improvement in the control of pain is still possible as pain management by clinicians and in the community is suboptimal. ${ }^{11-13}$ Although recommendations state that opioids should be combined with laxatives to prevent constipation, and might be combined with antiemetics to prevent nausea, many doctors still prescribe opioids without a simultaneous laxative. ${ }^{14-16}$ Financial issues are acknowledged to be important at the end-of-life ${ }^{17}$; however, with respect to medication this is not an issue as the costs of pain medication for long-term use is reimbursed in The Netherlands by the health care system.

Data about the treatment of pain and the prescribing of pain medication are often derived from specialised settings, ${ }^{18,19}$ and these are not always transposable to the community as the prevalence and treatment of pain differ between settings. ${ }^{10}$ Other studies restrict their study population to cancer patients. ${ }^{20,21}$ To the best of our knowledge, there is no study in primary care that has measured the prescribing of pain medication in a general population that includes cancer and non-cancer patients receiving palliative care at home from their GPs.

This study investigates the following research question: what pain and adjuvant medication is prescribed in patients receiving palliative care at home in general practice in The Netherlands, and how does the proportion of patients prescribed non-opioid analgesics, weak-opioids and strong opioids change during the last 3 months of life?

\section{METHODS}

\section{Patient selection}

The data used in this study were obtained from the second Dutch National Survey of General Practice (DNSGP-2), in which a sample of 104 Dutch general practices with 195 GPs registered the content of all patient/GP contacts in a 1-year period. ${ }^{22}$ The participating GPs were representative of all Dutch GPs $(\mathrm{n}=7217) .{ }^{22}$ The GPs coded the symptoms or diseases according to the International Classification of Primary Care. ${ }^{23}$ The 1-year period of each practice ended between April 2001 and January 2002. Data from nine practices were excluded: four practices delivered incomplete data and five practices were excluded because the data did not meet the quality criteria. The listed population of the remaining 95 practices was 374070 patients. In these practices 2169 patients died during the study period $(0.6 \%)$.

At the end of the study period, the GPs received a retrospective post-mortem questionnaire for each patient who died during the survey year. They reported the patient's underlying disease, and labelled each patient who received palliative care. The GP's own subjective label was chosen because this allows all the factors which in the perception of the labeller are related to palliative care to be taken into account. The labelling of the patient served as the first inclusion criterion. As all patients died during the study period, to ensure that we had an observation period of at least 3 months for each patient, the second inclusion criterion was that the patient died at least 3 months after the start of the prospective study. 


\section{[TABLE 1]}

\section{Prescriptions}

All prescriptions were derived from the database of the DNSGP-2 and contained digitally recorded information about the prescribed drugs, including the Anatomical Therapeutic Chemical classification code (ATC-code).${ }^{24} \mathrm{We}$ included all analgesics, with the exception of anti-depressants and neuroleptics, and classified them in three classes: non-opioid analgesics, weak opioids and strong opioids (see Table 1). Of the adjuvant drugs prescribed to control adverse effects, ${ }^{9}$ we included laxatives and anti-emetics.

\section{[TABLE 2]}

\section{Measurements}

Steps in theWHOanalgesic ladder: for each patient we analysed whether, and if so how many weeks before death, each of the three classes of analgesics had been prescribed during the 3 months observation period.

First prescription: each prescription was recorded as a first issue or a repeat prescription. A first prescription was defined as such when it was the first prescription in the observation period, and when it had not prescribed in the preceding 6 months. When a drug was first prescribed, the number of weeks between the date of prescription and the patient's death was calculated.

Combination with laxatives and anti-emetics: for each patient who was prescribed an opioid, we specified whether any laxative or anti-emetic had been prescribed.

\section{Analysis}

Descriptive analyses were carried out for patient characteristics and for the most frequently prescribed drugs in the three steps of the WHO analgesic ladder.

Differences in prescribing between sub-populations were calculated for medication initiated before the observation period, and over the last 3 months of life, for the characteristics gender, age and underlying disease, i.e. cancer versus non-cancer patients, using $\chi$ square test $(\alpha=0.05)$. For both cancer and non-cancer patients, we analysed changes in prescribing during the last 3 months of life by calculating the cumulative proportion of patients prescribed a drug in each of the three classes, starting at 3 months before the patient's death. The week in which the drug was first prescribed counted as the starting point. Furthermore, we analysed increases in the prescribed class of analgesics during the last 3 months and whether laxatives or antiemetics were prescribed as concomitant drugs in patients prescribed weak or strong opioids.

\section{RESULTS}

Out of the 2169 questionnaires sent to GPs, 1760 were returned (81\%), and 1596 were filled in completely (74\% valid response rate). In total, $736(46 \%)$ of patients received palliative care and 425 patients had an observation period of at least 3 months before death.

Characteristics of the patients studied are presented in Table 2.

\section{[TABLE 2]}

Of all patients who received palliative care, $73 \%$ were prescribed at least one drug for pain during the observation period (Table 3). Of these patients, 31\% received this prescription before the observation period. For most of these patients, the prescriptions were for non-opioid analgesics, with paracetamol prescribed for $14 \%$ of the patients. Weak and strong opioids were prescribed for 5.6 and $6.4 \%$ of the patients at 3 months before the patient's death. During the observation period, $55 \%$ of the patients received a non-opioid prescription, $21 \%$ a weak opioid prescription and $51 \%$ a prescription for a strong opioid. More cancer patients than non-cancer patients received a prescription for a strong opioid at 3 months before death and over the full observation period.

Table 4 shows that during the full observation period, there were no differences by gender in the proportion of patients who were prescribed pain medication.

Relatively more younger patients were prescribed a strong opioid than were older patients. 


\section{[TABLE 3]}

\section{Prescribing different classes of analgesics during the last 3 months of life}

Figures 1 and 2 show the proportion of cancer and noncancer patients who were prescribed no drug, and at least one drug from any of the three analgesic classes in the 3 months preceding death. At 3 months before death, the proportion of cancer patients who had no prescription was $65 \%$ compared to $73 \%$ for non-cancer patients. This proportion decreased gradually towards death for both cancer and non-cancer patients, with a steeper decrease in the last week, resulting in $19 \%$ of the cancer patients and $36 \%$ of the non-cancer patients having received no prescription over the observation period. During the last 3 months of life the proportion of patients who were prescribed a non-opioid analgesic or a weak opioid analgesic increased gradually. The proportion of patients prescribed a strong opioid showed a considerable increase starting at 3 weeks before death for cancer patients, and 1 week later for non-cancer patients.

Increase in analgesic classes and prescribing co-medication to treat adverse effects Table 5 shows that in the 3-month time frame, $16 \%$ of all patients were prescribed a strong opioid without firstly being prescribed a weak opioid. This occurred more frequently in cancer than in non-cancer patients $(p=0.016)$. Out of the 29 patients prescribed only a weak opioid and the 215 patients prescribed a strong opioid, respectively 59 and $46 \%$ were not prescribed a laxative during the last 3 months of life. For all patients prescribed a weak and/or a strong opioid the proportion of not prescribing any laxative was $48 \%$.

In the patients who were prescribed an opioid more than 2 weeks before death, $46 \%$ was prescribed a laxative, compared to $60 \%$ of the patients who were prescribed an opioid in the last 2 weeks of life. Not prescribing a laxative was more frequent in non-cancer patients than in cancer patients $(\mathrm{p}=0.006)$. In total, $29 \%(n=70)$ of patients prescribed an opioid received a prescription against nausea.

\section{[TABLE 4]}

\section{DISCUSSION}

Summary of main findings In the last 3 months before death, $73 \%$ of patients receiving palliative care from their GP were prescribed pain medication: $55 \%$ a non-opioid analgesic, $21 \%$ a weak opioid, and $51 \%$ a strong opioid. Over the full period, relatively more younger than older patients were prescribed a strong opioid. During the last 3 months of life, the proportion of patients prescribed a non-opioid or a weak opioid increased gradually.

The proportion of patients prescribed a strong opioid increased considerably nearing the patient's death.

About one-third of the non-cancer patients were prescribed strong opioids, most of them starting in the last 2 weeks before death. In $48 \%$ of all patients with an opioid prescription, the GP did not prescribe a laxative.

\section{Strengths and the limitations of this study}

Limitations of this study were that no information was obtained about the severity of the pain, or whether the drugs prescribed were used by the patient.

\section{[FIGURE 1]}

\section{[FIGURE 2]}

Furthermore, we were unable to measure whether, in the prescriber's or the patient's opinion, pain control had been achieved. Also, we had no details about dose adjustments, hence these were not included in the analysis. We did not include drugs started 3 months before the patient's death.

This study was embedded in the second Dutch National Survey of General Practice, which has generated solid data due to its quality and size, ${ }^{22}$ and has allowed us to analyse the prescribing of pain medication longitudinally over the last 3 months before a patient's death. The total response rate of $74 \%$ for the additional questionnaire was high compared to mean response rates of $61 \%$ reported in population-based studies carried out in general practice. ${ }^{25}$ As most studies in palliative care are limited to cancer patients, ${ }^{26}$ a further strength of this study is that we included both cancer and non-cancer patients. 


\section{[TABLE 5]}

\section{Comparison with existing literature}

A total of $27 \%$ of all patients in general practice receiving palliative care, and $19 \%$ of cancer patients, were not prescribed analgesics. Although pain is common in cancer patients, studies report a wide variation in its prevalence (33-88\%). ${ }^{27}$ However, the proportion of patients receiving a prescription for analgesics in our study is comparable to numbers found in other studies. ${ }^{10,27}$ Weak opioids, step 2 of the WHO analgesic ladder, are prescribed to $27 \%$ of the cancer population, which is substantially lower than in Italy $(52 \%)^{10}$ and Germany $(60 \%){ }^{28}$ This may be due to the fact that in both studies doctors were instructed to follow the WHO analgesic ladder. Also differences in knowledge and attitude towards strong opioids (e.g. 'opiophobia') might explain differences in prescribing across Europe. ${ }^{29}$ Our study shows that GPs often pass over weak opioids, and suggests that for the optimal management of pain, patients might benefit from the omission of step 2 of the WHO analgesic ladder, as is common practice and advised in recent Dutch guidelines ${ }^{30}$ and also suggested by other authors. ${ }^{31,32}$ Reasons for the omission of weak opioids may be that they frequently induce side effects such as nausea and constipation. ${ }^{33,34}$ Nearing end of life, another reason for prescribing a strong opioid without firstly prescribing a weak one may be that it is more important to achieve pain control quickly than to explore whether it could first be controlled with a weaker opioid.

It is striking that the increase in opioid prescribing occurs in non-cancer as well as in cancer patients, as pain is less common in non-cancer diseases. Possibly non-cancer patients share with cancer patients an increasing need for strong opioids to manage pain and/ or dyspnea. ${ }^{35,36}$ The prescribing of opioids in noncancer patients may reflect a typical pattern, with an increase in pain starting 2 weeks before death. It might also be that GPs are reluctant to prescribe strong opioids for non-cancer patients ${ }^{37-39}$ until death is close.

A point of concern is the lack of prescribing of comedication with opioids. Antiemetics are prescribed in only $27 \%$ of cases. In $48 \%$, no laxative has been prescribed. This proportion is comparable to in the findings of other studies. ${ }^{20,40}$ On the other hand, this number is low as compared to existing guidelines, that advise to combine strong opioids with laxatives. ${ }^{9,41,42}$ This study shows that GPs do not act according to these guidelines. Co-prescribing of laxatives and antiemetics needs more attention in education and attention of-and cooperation with - other health care professionals, such as pharmacists. ${ }^{16}$ Also, regular evaluation of the medication regimen might enhance the use of laxatives. ${ }^{43}$

Finally, we found that $34 \%$ of patients receive fentanyl via a transdermal patch. This could be an indication that GPs prescribe the fentanyl patch more often than advised in the WHO recommendations, which recommend - if possible — oral administration of strong opioids. ${ }^{9}$ It appears that the practical advantages of the use of the transdermal patches for many patients and their GPs outweigh those of oral dosing, a trend seen in other countries as well. ${ }^{44}$

\section{Implications for future research or clinical practice}

In total, $27 \%$ of patients receiving end-of-life care in general practice are not prescribed analgesics. Future, studies need to investigate why: because there is no need for pharmacological pain management, or because GPs do not manage pain adequately. Pain management for non-cancer patients also needs attention, especially in the period nearing death. To optimise pain management, we need to know why current practice with regard to the WHO analgesic ladder and the prescription of laxatives differs from the guidelines. The possibility that greater awareness and education in general practice over recent years has led to new insights into the optimising of pain management in palliative care which are not reflected in the guidelines cannot be excluded. Also, we need to know how we can optimally manage pain in non-cancer patients nearing the end of life.

\section{KEY POINTS}

Many patients were prescribed a strong opioid without a weak opioid being prescribed first.

About half of patients were prescribed an opioid without a laxative being prescribed.

- About one third of the non-cancer patients were prescribed strong opioids, mostly commencing only in the last 2 weeks before death. 
Borgsteede, S.D., Deliens, L., Zuurmond, W.W.A., Schellevis, F., Willems, D.L., Wal, G. van der, Eijk, J.T.Mt van. Prescribing of pain medication in palliative care: a survey in general practice. Pharmacoepidemiology anc Drug Safety: 2009, 18(1), 16-23

\section{REFERENCES}

1. Charlton RC. Attitudes towards care of the dying: a questionnaire survey of general practice attenders.

Fam Pract 1991; 8(4): 356-359.

2. Dunlop RJ, Davies RJ, Fermont D. Preferred versus actual place of death; a hospital palliative care support team study. Palliat Med 1989; 3: 197-201.

3. Townsend J, Frank AO, Fermont D, et al. Terminal cancer care and patients' preference for place of death: a prospective study. Br Med J 1990; 301(6749): 415-417.

4. European primary care. Health Council of The Netherlands, editor.

20E. The Hague: Health Council of the Netherlands, 2004.

5. Francke AL,Willems DL. Palliatieve zorg vandaag en morgen [Palliative care today and tomorrow], Elsevier gezondheidszorg: Maarssen, 2000.

6. Janssens RJ, Ten Have HA. The concept of palliative care in The Netherlands. Palliat Med 2001; 15(6): 481-486.

7. Mercadante S, Fulfaro F, Casuccio A. The impact of home palliative care on symptoms in advanced cancer patients. Support Care Cancer 2000; 8(4): 307-310.

8. Potter J, Hami F, Bryan T, Quigley C. Symptoms in 400 patients referred to palliative care services: prevalence and patterns. Palliat Med 2003; 17(4): 310-314.

9. WHO. Cancer Pain Relief With a Guide to Opioid Availability (2nd Edn), World Health Organization: Geneva, 1986.

10. Mercadante S. Pain treatment and outcomes for patients with advanced cancer who receive follow-up care at home. Cancer 1999; 85(8): 1849- 1858.

11. Levy MH. Pharmacologic treatment of cancer pain. N Engl J Med 1996; 335(15): 1124-1132.

12. Sloan PA, Donnelly MB, Schwartz RW, Sloan DA. Cancer pain assessment and management by housestaff. Pain 1996; 67(2-3): 475-481.

13. Hanlon JT, Fillenbaum GG, Studenski SA, Ziqubu-Page T, Wall WE, Jr. Factors associated with suboptimal analgesic use in communitydwelling elderly. Ann Pharmacother 1996; 30(7-8): 739-744.

14. Klaschik E, Nauck F, Ostgathe C. Constipation-modern laxative therapy. Support Care Cancer 2003; 11(11): 679-685.

15. Herndon CM, Jackson KC, Hallin PA. Management of opioid-induced gastrointestinal effects in patients receiving palliative care. Pharmacotherapy 2002; 22(2): 240-250.

16. Bouvy ML, Buurma H, Egberts TC. Laxative prescribing in relation to opioid use and the influence of pharmacy-based intervention. J Clin Pharm Ther 2002; 27(2): 107-110.

17. Hanratty $B$, Holland $P$, Jacoby $A$, Whitehead M. Financial stress and strain associated with terminal cancer a review of the evidence. Palliat Med 2007; 21(7): 595-607.

18. Klepstad P, Kaasa S, Cherny N, Hanks G, De Conno F. Pain and pain treatments in European palliative care units. A. cross-sectional survey from the European Association for Palliative Care Research Network. Palliat Med 2005; 19(6): 477-484.

19. Jenkins CA, Taube AW, Turner K, Hanson J, Bruera E. Initial demographic, symptom, and medication profiles in patients admitted to continuing palliative care units. J Pain Symptom Manage 1998; 16(3): 163170.

20. Barclay S, Todd C, Grande G, Lipscombe J. Controlling cancer pain in primary care: the prescribing habits and knowledge base of general practitioners. J Pain Symptom Manage 2002; 23(5): 383-392.

21. Lang CC, Beardon PHG, Ladlow M, Macrae W. Drug management of pain caused by cancer: a study of general practitioners' treatment attitudes and practices. Palliat Med 1992; 6: 246-252.

22. Westert GP, Schellevis FG, De Bakker DH, Groenewegen PP, Bensing JM, Van der Zee J. Monitoring health inequalities through general practice: the Second Dutch National Survey of General Practice. Eur J Public Health 2005; 15(1): 59-65.

23. Lamberts H, Woods M, Hofmans-Okkes I. The International Classification of Primary Care in the European Community, Oxford University Press: Oxford, 1993.

24. WHO Collaborating Centre for Drug Statistics Methodology, ATC index with DDDs, World Health Organization: Oslo, 2002.

25. Sibbald B, Addington-Hall J, Brenneman D, Freeling P. Telephone versus postal surveys of general practitioners: methodological considerations.

Br J Gen Pract 1994; 44(384): 297-300.

26. George LK. Research design in end-of-life research: state of science.

Gerontologist 2002; 42 Spec No 3: 86-98.

27. Higginson IJ, Hearn J. A multicenter evaluation of cancer pain control by palliative care teams. J Pain Symptom Manage 1997; 14(1): 29-35. 
Borgsteede, S.D., Deliens, L., Zuurmond, W.W.A., Schellevis, F., Willems, D.L., Wal, G. van der, Eijk, J.T.Mt van. Prescribing of pain medication in palliative care: a survey in general practice. Pharmacoepidemiology anc Drug Safety: 2009, 18(1), 16-23

28. Meuser T, Pietruck C, Radbruch L, Stute P, Lehmann KA, Grond S.

Symptoms during cancer pain treatment following WHO-guidelines: a longitudinal follow-up study of symptom prevalence, severity and etiology. Pain 2001; 93(3): 247-257.

29. Bilsen J, Norup M, Deliens L, et al. Drugs used to alleviate symptoms with life shortening as a possible side effect: end-of-life care in six European countries. J Pain Symptom Manage 31: 2006; 111-121.

30. De Graeff A, Hesselman GM, Krol RJA, Kuyper EH, Vollaard EJ.

Palliatieve zorg. Richtlijnen voor de praktijk [Palliative care. Guidelines for practice], VIKC Nederland: Utrecht, 2006.

31. MaltoniM, Scarpi E, Modonesi C, et al. Avalidation study of the WHO analgesic ladder: a two-step vs. three-step strategy. Support Care Cancer 2005; 13(11): 888-894.

32. Davis MP, Walsh $D$, Lagman R, LeGrand SB. Controversies in pharmacotherapy of pain management. Lancet Oncol. 2005; 6(9): 696-704.

33. Leppert W, Luczak J. The role of tramadol in cancer pain treatment-a review. Support Care Cancer 2005; 13(1): 5-17.

34. Rodriguez RF, Bravo LE, Castro F, et al. Incidence of weak opioids adverse events in the management of cancer pain: a double-blind comparative trial. J Palliat Med 2007; 10(1): 56-60.

35. Breivik H. Opioids in chronic non-cancer pain, indications and controversies. Eur J Pain 2005; 9(2): 127-130.

36. Jennings AL, Davies AN, Higgins JP, Gibbs JS, Broadley KE.

A systematic review of the use of opioids in the management of dyspnoea. Thorax 2002; 57(11): 939-944.

37. Von Roenn JH, Cleeland CS, Gonin R, Hatfield AK, Pandya KJ.

Physician attitudes and practice in cancer pain management. A. survey from the Eastern Cooperative Oncology Group. Ann Intern Med 1993; 119(2): 121-126.

38. Turk DC, Okifuji A. What factors affect physicians' decisions to prescribe opioids for chronic noncancer pain patients? Clin J Pain 1997; 13(4): 330-336.

39. Hutchinson K, Moreland AM, de CWA, Weinman J, Horne R. Exploring beliefs and practice of opioid prescribing for persistent non-cancer pain by general practitioners. Eur J Pain 2007; 11(1): 93-98.

40. Seamark DA, Lawrence C, Gilbert J. Characteristics of referrals to an inpatient hospice and a survey of general practitioner perceptions of palliative care. J R Soc Med 1996; 89(2): 79-84.

41. HanksGW, Conno F, Cherny N, et al. Morphine and alternative opioids in cancer pain: the EAPC recommendations. Br J Cancer 2001; 84(5): 587-593.

42. Gordon DB, Dahl JL, Miaskowski C, et al. American pain society recommendations for improving the quality of acute and cancer pain management: American Pain Society Quality of Care Task Force. Arch Intern Med 2005; 165(14): 1574-1580.

43. Hosia-Randell $\mathrm{H}$, Suominen M, Muurinen S, Pitkala KH. Use of laxatives among older nursing home residents in Helsinki, Finland.

Drugs Aging 2007; 24(2): 147-154.

44. Ripamonti C, Fagnoni E, Campa T, Brunelli C, de CF. Is the use of transdermal fentanyl inappropriate according to the WHO guidelines and the EAPC recommendations? A study of cancer patients in Italy. Support Care Cancer 2006; 14(5): 400-407. 
Borgsteede, S.D., Deliens, L., Zuurmond, W.W.A., Schellevis, F., Willems, D.L., Wal, G. van der, Eijk, J.T.Mt van. Prescribing of pain medication in palliative care: a survey in general practice. Pharmacoepidemiology anc Drug Safety: 2009, 18(1), 16-23

\section{TABLES AND FIGURES}

Table 1. Prescribed pain medication and their corresponding ATC-codes classified in non-opioid analgesics, weak and strong opioids

\begin{tabular}{lll}
\hline Class of drug & ATC-code & Drug name \\
\hline Non-opioid analgesics & N02BE01 & $\begin{array}{l}\text { Paracetamol }^{*} \\
\text { N02AA59 }\end{array}$ \\
& Paracetamol (+codeine) \\
& Paracetamol (+other) \\
& M01AE01 & $\begin{array}{l}\text { (excl.psycholeptics) } \\
\text { Diclofenac }\end{array}$ \\
& M01 (other) & Other NSAIDs \\
& N02BA & Salicylic acid + derivates \\
& N02AA59 & Codeine (+paracetamol) \\
Weak opioids & N02BE51 & Codeine (+paracetamol) \\
& N02AX02 & Tramadol \\
& N02AC04 & Dextropropoxyphene \\
& N02AA01 & Morphine \\
Strong opioids & N02BA03 & Fentanyl (transdermal patch) \\
& N02 & Other \\
Laxatives & A06 & \\
Antiemitics & A03FA & \\
& A04 & \\
\hline
\end{tabular}

* Paracetamol and/or codeine were prescribed alone, or in combinations. Therefore, different ATC-codes could identify these drugs.

Table 2. Characteristics of patients who received palliative care in general practice $(N=425)$.

$$
\%(N=425)
$$

\begin{tabular}{lc}
\hline Sex & \\
Male & 47 \\
Female & 53 \\
Age (years) & 28 \\
$<70$ & 24 \\
$70-79$ & 32 \\
$80-89$ & 16 \\
$\geq 90$ & $76.9(14.0)$ \\
Mean age (SD) & \\
Underlying disease* & 55 \\
Cancer & 45 \\
Non-cancer & 11 \\
Heart failure & 3.1 \\
COPD & 26 \\
Other disease & 4.5 \\
Multiple non-cancer diseases & \\
\hline
\end{tabular}

*Number of missing values for underlying diseases was 3 . 
Borgsteede, S.D., Deliens, L., Zuurmond, W.W.A., Schellevis, F., Willems, D.L., Wal, G. van der, Eijk, J.T.MY van. Prescribing of pain medication in palliative care: a survey in general practice. Pharmacoepidemiology anc Drug Safety: 2009, 18(1), 16-23

Table 3. Proportion of cancer and non-cancer patients who received palliative care in general practice and prescribed pain medication during the last 3 months of life $(N=422)$

\begin{tabular}{|c|c|c|c|c|}
\hline \multicolumn{5}{|c|}{ (A) Pain medication initiated before the observation period ${ }^{*}$} \\
\hline Prescribed drug & Cancer $^{\dagger}(n=234)$ & Non-cancer $(n=188)$ & $P(\chi$-square $)$ & Total $(n=422)$ \\
\hline No prescription (\%) & 65 & 73 & 0.113 & 69 \\
\hline At least one prescription $(\%)$ & 35 & 27 & & 31 \\
\hline Non-opioid analgesics $(\%)$ & 28 & 24 & 0.315 & 26 \\
\hline Paracetamol (\%) & 15 & 13 & 0.675 & 14 \\
\hline Diclofenac $(\%)$ & 12 & 5.3 & 0.017 & 9.2 \\
\hline Other NSAIDs $(\%)$ & 7.3 & 7.4 & 1.000 & 7.3 \\
\hline Weak opioids $(\%)$ & 6.8 & 4.3 & 0.295 & 5.6 \\
\hline Codeine $(\%)$ & 2.6 & 2.7 & 1.000 & 2.6 \\
\hline Tramadol + other ${ }^{\ddagger}(\%)$ & 4.3 & 2.1 & 0.280 & 3.3 \\
\hline Strong opioids $(\%)$ & 8.5 & 3.7 & 0.047 & 6.4 \\
\hline Morphine (\%) & 5.6 & 2.1 & 0.085 & 4.0 \\
\hline Fentanyl $(\%)$ & 4.7 & 2.1 & 0.192 & 3.5 \\
\hline Other $(\%)$ & 0.4 & 0.0 & 1.000 & 0.2 \\
\hline
\end{tabular}

(B) Pain medication prescribed during the full observation period

\begin{tabular}{lccc}
\hline Prescribed drug & Cancer $^{\dagger}(n=234)$ & Non-cancer $(n=188)$ & $P(\chi$-square $)$ \\
\hline No prescription (\%) & 19 & 36 & 0.000 \\
At least one prescription (\%) & 81 & 64 & 27 \\
Non-opioid analgesics (\%) & 62 & 46 & 73 \\
Paracetamol (\%) & 39 & 34 & 0.001 \\
Diclofenac (\%) & 29 & 13 & 0.312 \\
Other NSAIDs (\%) & 17 & 11 & 0.000 \\
Weak opioids (\%) & 27 & 14 & 0.095 \\
Codeine (\%) & 12 & 9.6 & 0.001 \\
Tramadol +other $(\%)$ & 19 & 7.4 & 0.530 \\
Strong opioids (\%) & 62 & 37 & 0.001 \\
Morphine (\%) & 39 & 24 & 21 \\
Fentanyl (\%) & 45 & 20 & 14 \\
Other (\%) & 5.1 & 1.6 & 14 \\
\hline
\end{tabular}

*A drug was initiated before the observation period, as it was identified as repeat prescribing.

${ }^{\dagger}$ Number of missing values for underlying diseases was 3 .

${ }^{\ddagger}$ One patient was prescribed dextropropoxyphene.

Table 4. Proportion of palliative care patients in general practice by gender and age category prescribed at least one analgesic in different classes of pain medication $(n=425)$

\begin{tabular}{|c|c|c|c|c|c|c|}
\hline \multicolumn{7}{|c|}{ (A) Pain medication initiated before the observation period ${ }^{*}$} \\
\hline & & No prescription & At least one prescription & Non-opioid analgesic & Weak opioid & Strong opioid \\
\hline \multirow[t]{5}{*}{ Age category $(N=425)$} & $<70$ years $(\%)$ & 72 & 28 & 22 & 6.8 & 9.3 \\
\hline & $70-79$ years $(\%)$ & 69 & 31 & 26 & 5.0 & 5.9 \\
\hline & $80-89$ years $(\%)$ & 65 & 35 & 29 & 7.4 & 5.9 \\
\hline & $\geq 90$ years $(\%)$ & 71 & 29 & 27 & 1.4 & 2.9 \\
\hline & $P(\chi \text {-square })^{\dagger}$ & & 0.557 & 0.290 & 0.329 & 0.090 \\
\hline \multirow[t]{3}{*}{ Gender $(N=425)$} & Male $(\%)$ & 74 & 26 & 24 & 7.0 & 6.0 \\
\hline & Female (\%) & 65 & 35 & 28 & 4.5 & 6.7 \\
\hline & $P(\chi$-square $)$ & & 0.059 & 0.378 & 0.297 & 0.843 \\
\hline
\end{tabular}

(B) Pain medication prescribed during the full observation period

\begin{tabular}{|c|c|c|c|c|c|c|}
\hline & & No prescription & At least one prescription & Non-opioid analgesic & Weak opioid & Strong opioid \\
\hline \multirow[t]{5}{*}{ Age category $(N=425)$} & $<70$ years $(\%)$ & 21 & 79 & 54 & 31 & 63 \\
\hline & $70-79$ years $(\%)$ & 28 & 72 & 61 & 21 & 46 \\
\hline & $80-89$ years $(\%)$ & 28 & 72 & 52 & 19 & 46 \\
\hline & $\geq 90$ years $(\%)$ & 34 & 66 & 53 & 10 & 46 \\
\hline & $\bar{P}(\chi \text {-square })^{\dagger}$ & & 0.060 & 0.581 & 0.001 & 0.014 \\
\hline \multirow[t]{3}{*}{ Gender $(N=425)$} & Male $(\%)$ & 30 & 70 & 53 & 22 & 52 \\
\hline & Female (\%) & 25 & 75 & 57 & 21 & 50 \\
\hline & $P(\chi$-square $)$ & & 0.231 & 0.495 & 0.812 & 0.698 \\
\hline
\end{tabular}

*A drug was initiated before the observation period, as it was identified as repeat prescribing.

${ }^{\dagger} \chi$-Square for trend. Linear-by-linear association. 
Borgsteede, S.D., Deliens, L., Zuurmond, W.W.A., Schellevis, F., Willems, D.L., Wal, G. van der, Eijk, J.T.Mt van. Prescribing of pain medication in palliative care: a survey in general practice. Pharmacoepidemiology and Drug Safety: 2009, 18(1), 16-23

Figure 1. Proportion of cancer patients in the weeks preceding death who were prescribed no analgesic and at least one analgesic of the following classes: nonopioid analgesics, weak opioids or the strong opioids ladder $(\mathrm{N}=234)$

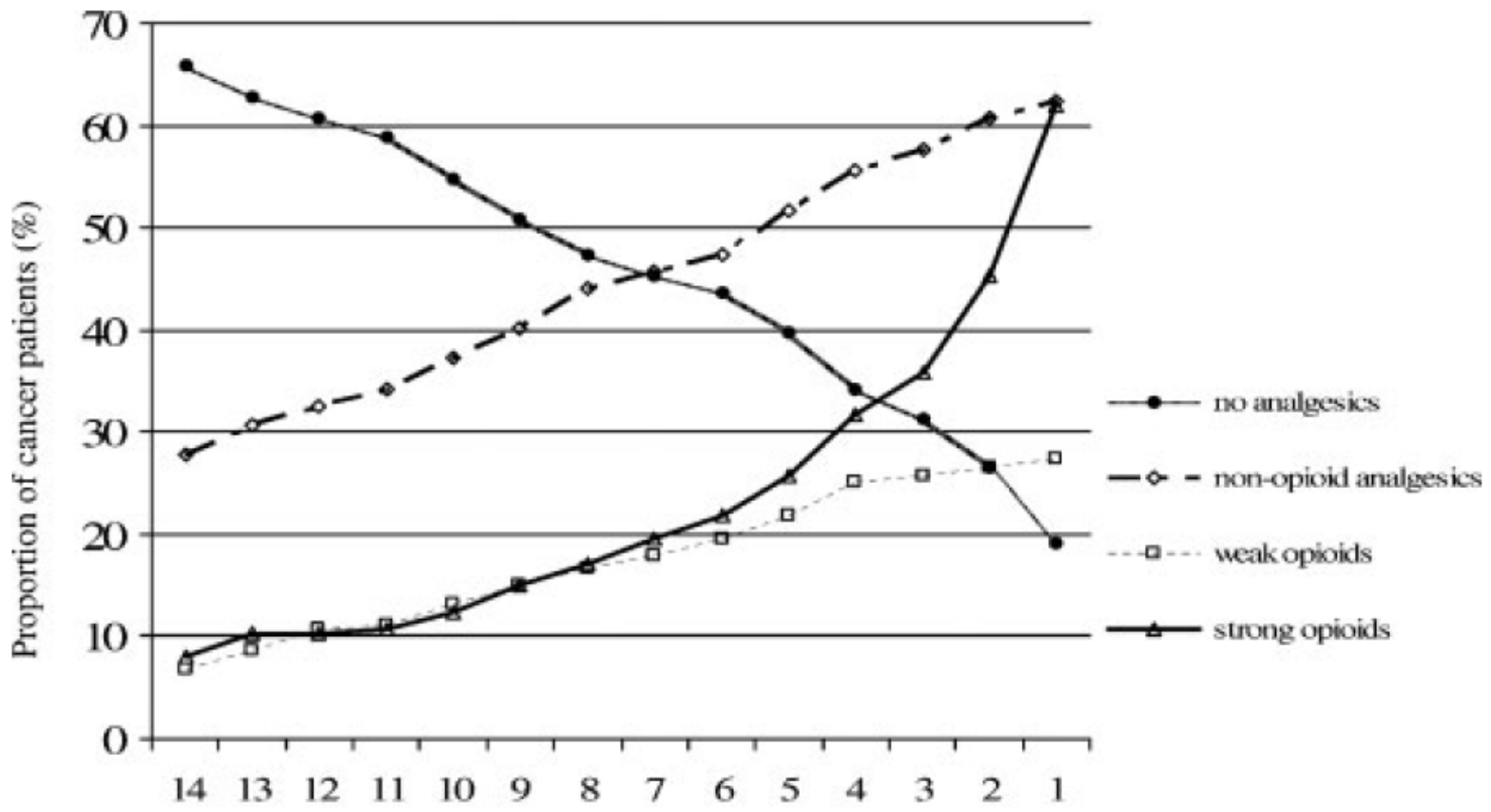

Number of weeks before the patient's death

Figure 2. Proportion of non-cancer patients in the weeks preceding death who were prescribed no analgesic and at least one analgesic of the following classes:

non-opioid analgesics, weak opioids or strong opioids ( $\mathrm{N}=1 / 4188)$

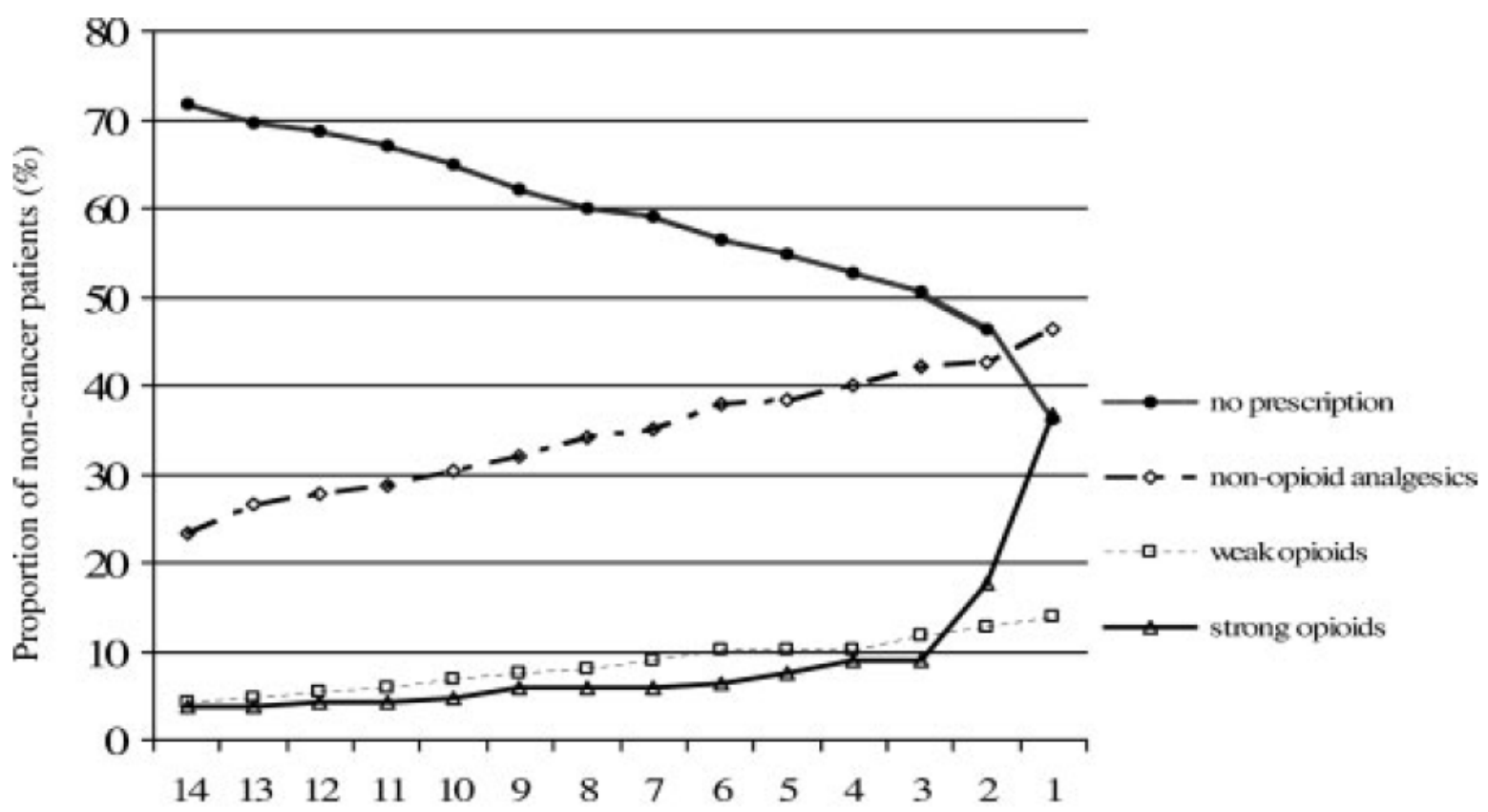

Number of weeks before the patient's death 